\title{
Research Paper: The Association Between Exercise and Psychological Wellbeing in Patients Undergoing Cardiac Surgery
}

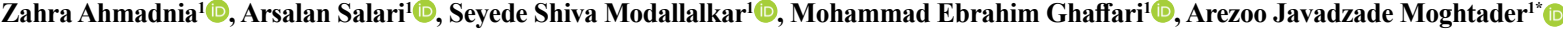

1. Cardiovascular Diseases Research Center, Department of Cardiology, Heshmat Hospital, School of Medicine, Guilan University of Medical Sciences, Rasht, Iran.

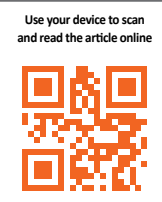

dettron: Ahmadnia, Z., Salari, A., Modallalkar, S. Sh., Ghaffari, M. E., \& Javadzade Moghtader, A. (2020). The Association Between Exercise and Psychological Wellbeing in Patients Undergoing Cardiac Surgery. Journal of Practice in Clinical Psychology, 8(2), 143-152. https://doi.org/10.32598/jpcp.8.2.671.1

https://doi.org/10.32598/jpcp.8.2.671.1

Keywords:

Exercise, Psychological wellbeing, Patients, Cardiac surgery

\section{ABSTRACT}

Objective: In recent years, psychology and psychotherapy have received particular attention, especially concerning hospitalized patients. Because of the growing number of mental disorders among patients undergoing cardiac surgery, it is necessary to identify factors affecting the mental health of these patients. The purpose of this research was to study the relationship between psychological wellbeing and exercise among patients undergoing cardiac surgery.

Methods: In this case-control study, 176 patients with Acute Coronary Syndrome (ACS) and one of their relatives (third-degree relatives) were investigated. The study data were collected through interviews with the patients. The study questionnaire had three parts comprising demographic, clinical, and Ryff standard questionnaires and exercise frequency (the average hours of exercise per day, and the number of days per week). To analyze the variables, the independent samples t-test and multiple linear regression models were used. The significance level was set as $<0.05$.

Results: In each group, 88 subjects were investigated. The results showed no significant difference between the two groups in the positive relationship $(\mathrm{P}=0.206)$ and autonomy $(\mathrm{P}=0.057)$ subscales. In other subscales and the total score of healthy subjects, the mean score was higher $(P<0.05)$. Also, there was a significant difference between the two groups in just the autonomy subscale $(\mathrm{P}=0.038)$. Furthermore, the increase in the number of exercise days, and especially 1 to 2 hours per day had a positive and significant effect on the total score and the subscale of autonomy.

Conclusion: Patients undergoing cardiac surgery should be encouraged to perform the exercise, which in turn improves their aspects of mental health such as psychological wellbeing.

* Corresponding Author:

Arezoo Javadzade Moghtader, Msc.

Address: Cardiovascular Diseases Research Center, Department of Cardiology, Heshmat Hospital, School of Medicine, Guilan University of Medical

Sciences, Rasht, Iran.

Tel: \pm 98 (31) 33618177

E-mail:gums.icrc@gmail.com 


\section{Highlights}

- Exercise could improve psychological wellbeing in patients undergoing cardiac surgery.

- The ability to progress by exercise could improve psychological health.

- The average score in athletes about the autonomy subscale alone was higher.

\section{Plain Language Summary}

Nowadays psychological wellbeing is one of the important subjects in the studies of chronic diseases. Cardiovascular diseases are caused or associated with some wrong behaviors of people, their psychological traits, stress, and anxiety. This study aimed to investigate the relationship between physical activity and psychological wellbeing in postoperative patients. It is known that the psychological wellbeing of an athlete's patient was remarkably high compared with non-athletes people. The results showed that the increase in the number of days spent in the exercise per week has a significant effect on the autonomy subscale. On the other hand, exercise about 1 to 2 hours per day could improve psychological wellbeing in postoperative patients. Exercise contributes both to the reduction of some psychological problems and to the increase in satisfaction from life. Sports provide interaction and communication and develop cooperation between individuals. As a result, physical activity is important for everyone and it is not only necessary to have good physical health, but also good psychological health so that people experience a better life, do better things.

\section{Introduction}

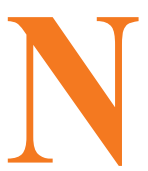

owadays and during this technological period, the incidence of cardiovascular diseases has increased in the world and our country, Iran (Etemad \& Esmaeil Nasab, 2012; Jeong et al., 2019). These diseases are among the most common chronic diseases and the leading causes of adult death throughout the world (Borji, Bastami, Bastami, Azami, \& Tavan, 2015). They have various treatments, including Coronary Artery Bypass Graft Surgery (CABG) (Neyse, Daneshmandi, Sadeghi Sharme, \& Ebadi, 2011). CABG is one of the most prevalent treatments being used for patients with coronary artery disease so that over 73 million people are treated by open-heart surgery in the USA each year (Bikmoradi, Harorani, Roshanaei, Moradkhani, \& Falahinia, 2016). Cardiovascular diseases and its treatments, especially open heart surgery negatively affect Psychological Wellbeing (PWB) and significantly reduces patient's satisfaction (Bikmoradi et al., 2016; Mahmoud Alilou, Bayat, \& Hosseini, 2016). Cardiovascular health is always associated with optimism and psychological wellbeing and positive psychological wellbeing independently protects individuals from risk factors for cardiovascular disease (Boehm, Trudel-Fitzgerald, Kivimaki, \& Kubzansky, 2015; Mohammadi et al., 2018). PWB is defined as the ability to find all the talents of an individual, including the following components: self-de- termination (sense of competence and ability to manage the environment around the individual), personal development (having continuous improvement), positive relationships with others (having warm communications), life goal, self-acceptance (having a positive attitude towards oneself), and environmental control (the ability to choose and create an appropriate environment) (Ryff, 2014). Patients with high psychological wellbeing have better mental health than patients with low psychological wellbeing (Mahmoud Alilou et al., 2016; Mohammadi et al., 2018). Research has indicated that the psychological problems caused by the initial diagnosis of Coronary Artery Disease (CAD) in some patients persistently remain even three years after CABG (Mahmoud Alilou et al., 2016). Therefore, continuous efforts are needed to reduce CVD risk. The health benefits of Physical Activity (PA) have been well-documented from the perspective of CVD and premature mortality (Lavie et al., 2015; Lee, Pate, Lavie, Sui, Church, \& Blair, 2014; Ricci \& Cunha, 2020). According to WHO, one way to reduce health costs and improve the health of people is by participating in physical activity (Kim, Kubzansky, Soo, \& Boehm, 2017). Regular body activity has significant and effective role in one's psychological health (Sohrabi, Abedanzade, Shetab Boushehri, Parsaei, \& Jahanbakhsh, 2017). Eric et al. concluded in a prospective study that PWB is the occurrence of chronic diseases and early mortality (Ricci \& Cunha, 2020). According to WHO, health is independently associated with the achievement and maintenance 
of physical activity. In other words, increasing physical activity in the final years of life can also increase the health level (Kim et al., 2017). Also, it has been reported that physical activity affects people's mental health (Fibbins, Lederman, \& Rosenbaum, 2020).

It should be noted that most patients cannot achieve the recommended levels of physical activity following an Acute Coronary Syndrome (ACS) (Huffman et al., 2019). The conducted research for improving the levels of activity has not concentrated on psychological wellbeing progress, which is independently preferred cardiac health and reduced cardiac re-hospitalizations rate (Ek et al., 2019; Huffman et al., 2019; Kronish, Diaz, Goldsmith, Moise, \& Schwartz, 2017). Hence, the majority of post-ACS patients do not achieve recommended levels of activity. Developed programs (e.g. cardiac rehabilitation) to promote activity may be beneficial, but they are typically time-intensive and attended by only a minority of patients (McMahon, Ades, \& Thompson, 2017). Therefore, in the present investigation, we aimed to study the relationship between physical activity and psychological wellbeing in post-operative patients.

\section{Methods}

This study was a cross-sectional study designed to investigate the relationship between psychological wellbeing and exercise in two groups. A total of 176 participants took part in this study that was equally divided into two groups of patients and healthy people (88 per group).

The first group consisted of patients suffering from Acute Coronary Syndrome (ACS) who had undergone CABG six months before the study. The samples were recruited from the patients, who referred to the Cardiac Clinic of Heshmat Hospital of Rasht City, Iran from February to July in 2016. The second group members were chosen from one of their relatives (third-degree) and consisted of individuals without any hospitalization experience regarding the cardiac disease, angiography or traditional angioplasty experience, tachycardia, chest pain, shortness of breath, and syncope. Both groups were homogenized according to age, gender, and education.

Both groups were 30 to 60 years old. All participants with the following criteria were excluded: 1 . The history of multiple sclerosis; 2. Sleep disorder; 3. Digestive disorders interfering with daily routines; 4 . Decrease in the function of joints and muscles; 5. Cognitive disorders and major mental disorders according to their medical history and participants' statements, which could interfere with the psychological wellbeing of the individuals.
Available sampling was done and the information on all subjects of the two groups was obtained. The study data were collected via interviews with the samples using the study questionnaire, which has three parts: the first part was demographic and clinical information, the second part was the Ryff standard questionnaire for the determination of psychological wellbeing, and the third part was the frequency of exercise presented as hours/ day and days/week.

Scales of Psychological Wellbeing (SPWB) was developed by Ryff in 1989. Ryff wellbeing scale (Hauser, Springer, \& Pudrovska, 2005) is composed of six subscales in accordance with the six factors of positive functioning, namely self-acceptance, positive relations with others, autonomy, purpose in life, personal growth, and environmental mastery. Each subscale contains three questions, which measures responses based on a 6-point Likert scale ( $1=$ strongly disagree to $6=$ strongly agree). The score for each subscale ranges from 3 to 18 . The minimum and maximum wellbeing total scores are 18 and 108 , respectively. The reliability and validity of this scale have already been confirmed in several studies (Krueger \& Schkade, 2008). The internal consistency of the subscales and their Cronbach alpha was reported to be between 0.77 and 0.90 (Van Dierendonck, 2004). Vahedi et al. assessed the reliability of this study using the split-half method and its Cronbach alpha was reported between 0.7 and 0.71 (Vahedi \& Ghanizadeh, 2008).

The obtained data were entered into SPSS version 22 and were analyzed using descriptive and inferential statistics. Meanwhile, the comparison between variables and psychological wellbeing was done by the Independent samples t-test. The relations between the independent variables and outcome measures were examined using multiple linear regression and a $\mathrm{P}$ value less than 0.05 was considered significant. The present study was approved by the local Ethics Committee of Guilan University of Medical Sciences (IR.GUMS.REC.1394.423).

\section{Results}

In this case-control study, 88 patients with heart disease and 88 healthy individuals were evaluated. About 59.1\% and $28.4 \%$, respectively were in the group of patients and healthy subjects. The Mean \pm SD age in the case group was $56.28 \pm 15.86$ years and in the healthy group $44.66 \pm 15.92$ years. In this study, we first compared the total score of psychological wellbeing and each of its subscales in cardiac patients and healthy people (Table 1). 
Table 1. Results of the overall comparison and subscales of psychological wellbeing in cardiac patients and healthy people

\begin{tabular}{|c|c|c|c|c|c|}
\hline Response & Group & No. & Mean $\pm S D$ & ta & Sig. \\
\hline \multirow{2}{*}{ Total score } & Patient & 88 & $80.50 \pm 10.44$ & \multirow{2}{*}{4.92} & \multirow{2}{*}{$<0.001$} \\
\hline & Healthy & 88 & $87.66 \pm 8.75$ & & \\
\hline \multirow{2}{*}{ Self-admission } & Patient & 88 & $14.14 \pm 3.15$ & \multirow{2}{*}{3.48} & \multirow{2}{*}{0.001} \\
\hline & Healthy & 88 & $15.64 \pm 2.53$ & & \\
\hline \multirow{2}{*}{ Positive relationship } & Patient & 88 & $14.38 \pm 3.87$ & \multirow{2}{*}{1.27} & \multirow{2}{*}{0.206} \\
\hline & Healthy & 88 & $15.02 \pm 2.82$ & & \\
\hline \multirow{2}{*}{ Autonomy } & Patient & 88 & $12.38 \pm 3.09$ & \multirow{2}{*}{1.91} & \multirow{2}{*}{0.057} \\
\hline & Healthy & 88 & $13.25 \pm 2.98$ & & \\
\hline \multirow{2}{*}{ Environmental mastery } & Patient & 88 & $14.60 \pm 3.03$ & \multirow{2}{*}{3.07} & \multirow{2}{*}{0.002} \\
\hline & Healthy & 88 & $15.91 \pm 2.60$ & & \\
\hline \multirow{2}{*}{ Objective life } & Patient & 88 & $11.23 \pm 2.98$ & \multirow{2}{*}{2.57} & \multirow{2}{*}{0.011} \\
\hline & Healthy & 88 & $12.35 \pm 2.82$ & & \\
\hline \multirow{2}{*}{ Personal growth } & Patient & 88 & $14.00 \pm 3.12$ & \multirow{2}{*}{3.30} & \multirow{2}{*}{0.001} \\
\hline & Healthy & 88 & $15.38 \pm 2.35$ & & \\
\hline
\end{tabular}

The independent samples t-test

The results showed no significant difference between the two groups regarding the positive relationship $(\mathrm{P}=0.206)$ and autonomy $(\mathrm{P}=0.057)$ subscales. Regarding the other subscales and the total score of healthy subjects, the mean score was higher $(\mathrm{P}<0.05)$.

Subsequently, the total score and subscales of psychological wellbeing in athletes were compared with those who did not exercise (Table 2). The results showed a significant difference between the two groups in the autonomy subscale alone. The average score in athletes was higher.

To investigate the effect of heart disease and exercise on the total score and each of the subscales of psychological wellbeing linear regression was used after moderating the effects of gender and age. The results are presented in Table 3. According to the results with an adjustment effect of gender and age, heart disease has a negative effect

Table 2. Results of comparison of total score and subscales of psychological wellbeing in athletes and non-athletes

\begin{tabular}{|c|c|c|c|c|c|}
\hline Response & Group & No. & Mean $\pm S D$ & ta & Sig. \\
\hline \multirow{2}{*}{ Total score } & No & 91 & $83.08 \pm 9.65$ & \multirow{2}{*}{1.34} & \multirow{2}{*}{0.180} \\
\hline & Yes & 85 & $85.15 \pm 10.83$ & & \\
\hline \multirow{2}{*}{ Self-admission } & No & 91 & $14.99 \pm 2.87$ & \multirow{2}{*}{0.48} & \multirow{2}{*}{0.634} \\
\hline & Yes & 85 & $14.78 \pm 3.03$ & & \\
\hline \multirow{2}{*}{ Positive relationship } & No & 91 & $14.65 \pm 3.18$ & \multirow{2}{*}{0.20} & \multirow{2}{*}{0.839} \\
\hline & Yes & 85 & $14.75 \pm 3.62$ & & \\
\hline \multirow{2}{*}{ Autonomy } & No & 91 & $12.35 \pm 2.92$ & \multirow{2}{*}{2.09} & \multirow{2}{*}{$0.03 \varepsilon$} \\
\hline & Yes & 85 & $13.31 \pm 3.14$ & & \\
\hline \multirow{2}{*}{ Environmental mastery } & No & 91 & $15.19 \pm 2.98$ & \multirow{2}{*}{0.33} & \multirow{2}{*}{0.745} \\
\hline & Yes & 85 & $15.33 \pm 2.80$ & & \\
\hline \multirow{2}{*}{ Objective life } & No & 91 & $11.57 \pm 3.02$ & \multirow{2}{*}{1.02} & \multirow{2}{*}{0.311} \\
\hline & Yes & 85 & $12.02 \pm 2.87$ & & \\
\hline \multirow{2}{*}{ Personal growth } & No & 91 & $14.33 \pm 2.94$ & \multirow{2}{*}{1.74} & \multirow{2}{*}{0.08} \\
\hline & Yes & 85 & $15.07 \pm 2.69$ & & \\
\hline
\end{tabular}

The independent samples t-test 
Table 3. Summary results of the effects of heart disease and exercise adjusted for age and sex effects on the psychological wellbeinga

\begin{tabular}{|c|c|c|c|c|c|c|}
\hline Response & Variable (Base) & B & Std. Error & Beta & $\mathbf{t}$ & Sig. \\
\hline \multirow{4}{*}{ Total score } & Age & 0.125 & 0.047 & 0.206 & 2.649 & 0.009 \\
\hline & Gender (Female) & -0.368 & 1.534 & -0.018 & -0.240 & 0.811 \\
\hline & Group (Patient) & 8.301 & 1.578 & 0.406 & 5.259 & $<0.001$ \\
\hline & Exercise & 2.543 & 1.491 & 0.124 & 1.706 & 0.090 \\
\hline \multirow{4}{*}{ Self-admission } & Age & 0.044 & 0.014 & 0.249 & 3.124 & 0.002 \\
\hline & Gender (Female) & -0.026 & 0.452 & -0.004 & -0.058 & 0.954 \\
\hline & Group (Patient) & 1.996 & 0.465 & 0.340 & 4.297 & $<0.001$ \\
\hline & Exercise & .018 & 0.439 & 0.003 & 0.041 & 0.967 \\
\hline \multirow{4}{*}{ Positive relationship } & Age & 0.033 & 0.017 & 0.166 & 1.983 & 0.049 \\
\hline & Gender (Female) & -0.001 & 0.545 & 0.000 & -0.002 & 0.999 \\
\hline & Group (Patient) & 1.010 & 0.561 & 0.149 & 1.800 & 0.074 \\
\hline & Exercise & 0.323 & 0.530 & 0.048 & 0.609 & 0.544 \\
\hline \multirow{4}{*}{ Autonomy } & Age & 0.006 & 0.015 & 0.035 & 0.416 & 0.678 \\
\hline & Gender (Female) & -0.039 & 0.489 & -0.006 & -0.080 & 0.936 \\
\hline & Group (Patient) & 0.861 & 0.503 & 0.141 & 1.713 & 0.089 \\
\hline & Exercise & 0.943 & 0.475 & 0.155 & 1.985 & 0.049 \\
\hline \multirow{4}{*}{ Environmental mastery } & Age & 0.067 & 0.013 & 0.390 & 5.047 & $<0.001$ \\
\hline & Gender (Female) & -0.355 & 0.429 & -0.061 & -0.827 & 0.409 \\
\hline & Group (Patient) & 1.927 & 0.441 & 0.334 & 4.366 & $<0.001$ \\
\hline & Exercise & 0.593 & 0.417 & 0.103 & 1.422 & 0.157 \\
\hline \multirow{4}{*}{ Objective life } & Age & -0.038 & 0.014 & -0.216 & -2.643 & 0.009 \\
\hline & Gender (Female) & -0.017 & 0.463 & -0.003 & -0.037 & 0.970 \\
\hline & Group (Patient) & 0.676 & 0.476 & 0.115 & 1.421 & 0.157 \\
\hline & Exercise & 0.061 & 0.450 & 0.010 & 0.136 & 0.892 \\
\hline \multirow{4}{*}{ Personal growth } & Age & 0.016 & 0.014 & 0.092 & 1.135 & 0.258 \\
\hline & Gender (Female) & -0.468 & 0.444 & -0.082 & -1.055 & 0.293 \\
\hline & Group (Patient) & 1.350 & 0.457 & 0.238 & 2.954 & 0.004 \\
\hline & Exercise & 0.781 & 0.432 & 0.138 & 1.810 & 0.072 \\
\hline
\end{tabular}

All analyses were done using multiple linear regression.

on the overall score and the subscales of self-admission, environmental mastery, and personal growth.

Next, the effect of the number of exercise days per week and the number of exercise hours per day was investigated on the total score of the psychological wellbeing and each of its subscales. The results are presented in Tables 4 and 5; only significant cases are presented. The results showed that the increase in the number of days spent in the exercise per week had a significant effect on the autonomy subscale. Also, 1 to 2 hours of exercise per day had a positive and significant effect on the total score and the subscale of autonomy.

\section{Discussion}

The purpose of this study was to investigate the relationship between exercise and wellbeing in patients undergoing cardiac surgery. The psychological wellbeing indicators examined in this study included self-acceptance, positive relations with others, autonomy, purpose in life, personal growth, and environmental mastery. The results showed no significant difference between positive relationship and autonomy subscales. In other subscales and the total score of healthy subjects, the mean score was higher. The findings of this study were in accordance with the study by Mahmoud Alilou et al. (2016). 
Table 4. Results of the evaluation of the number of exercise days per week on the subscale of autonomy

\begin{tabular}{cccccc}
\hline Variable (Base) & B & Std. Error & Beta & t & Sig. \\
\hline Age & 0.001 & 0.025 & 0.003 & 0.023 & 0.982 \\
\hline Gender (Female) & -0.249 & 0.744 & -0.040 & -0.335 & 0.738 \\
Group (Patient) & 0.066 & 0.754 & 0.011 & 0.088 & 0.930 \\
Exercise weekly & 0.333 & 0.164 & 0.225 & 2.030 & 0.046 \\
\hline & & & & PRACTICE In PSYCH \\
\hline
\end{tabular}

Table 5. Results of the study of the number of hours of exercise per day on the total score and the subscale of autonomy

\begin{tabular}{|c|c|c|c|c|c|c|}
\hline Response & Variable (Base) & B & Std. Error & Beta & $\mathbf{t}$ & Sig. \\
\hline \multirow{6}{*}{ Total score } & Age & 0.122 & 0.048 & 0.200 & 2.541 & 0.012 \\
\hline & Gender (Female) & -0.157 & 1.569 & -0.008 & -0.100 & 0.920 \\
\hline & Group (Patient) & 8.221 & 1.591 & 0.402 & 5.166 & 0.000 \\
\hline & Exercise $<1$ hour (none) & 2.265 & 1.732 & 0.100 & 1.308 & 0.193 \\
\hline & $\begin{array}{l}\text { Exercise } 1-2 \text { hours } \\
\text { (none) }\end{array}$ & 4.007 & 2.001 & 0.151 & 2.002 & 0.047 \\
\hline & $\begin{array}{l}\text { Exercise }>2 \text { hours } \\
\text { (none) }\end{array}$ & 0.708 & 3.698 & 0.014 & 0.191 & 0.848 \\
\hline \multirow{6}{*}{ Autonomy } & Age & 0.003 & 0.015 & 0.019 & 0.227 & 0.820 \\
\hline & Gender (Female) & 0.097 & 0.497 & 0.016 & 0.195 & 0.845 \\
\hline & Group (Patient) & 0.821 & 0.504 & 0.135 & 1.627 & 0.106 \\
\hline & Exercise $<1$ hour (none) & 0.619 & 0.549 & 0.092 & 1.128 & 0.261 \\
\hline & $\begin{array}{l}\text { Exercise } 1-2 \text { hours } \\
\text { (none) }\end{array}$ & 1.661 & 0.634 & 0.210 & 2.619 & 0.010 \\
\hline & $\begin{array}{c}\text { Exercise }>2 \text { hours } \\
\text { (none) }\end{array}$ & -0.143 & 1.172 & -0.010 & -0.122 & 0.903 \\
\hline
\end{tabular}

It seems that cardiac patients are in a special psychological position. They are incapable of doing everyday activities and need intensive care and supervision. They should be under special medication. Overall, regarding the psychological wellbeing context, they are at a lower level than the other people in society. Subsequently, the results demonstrated a significant difference between the two groups in the autonomy subscale alone. The average score in athletes was higher. In a study carried out by Steinmayr, Heyder, Naumburg, Michels, and Wirthwein (2018), it has been determined that subjective wellbeing levels of students who make physical exercise is higher than those who do not make physical exercise. Also, in another research by Habibi-Vatan, Noorbakhsh, Nourbakhsh, and Navabinejad (2017) who investigated psychological wellbeing in the female staff of Islamic Azad University, it was found that psychological wellbeing score in athletes was higher than other people. The results of this study support the findings of our research.

It seems that relationship positive PWB in patients with post-open heart surgery may have important im- plications, given the relationship between positive affect and lower risk of first ACS or overall mortality in healthy persons and the links between positive psychology and reduced mortality in chronic illnesses.

On the other hand, this result was different with Kashani Movahhed, Nikfarjad, Shahbazpoor, Davodzadeh, Molaei, \& Molla Mahmoudi (2018) study. The reason for the difference may be because of various geographical environments of research units, income, and social class.

In this study, the results represented that the increase in the number of days spent in the exercise week on the autonomy subscale has a significant effect. Also, the exercise of 1 to 2 hours per day on the total score and the subscale of autonomy had a positive and significant effect. According to the study by Gül, Çağlayan, and Akandere (2017), sports training ( 2 hours per week) along with the curriculum affects the psychological wellbeing dimensions of the students. This issue supports the results of our study. These findings are consistent with prior work illustrating the links between positive psychological 
wellbeing and greater physical activity in healthy individuals, medically-ill persons, and post-ACS patients.

As a result, physical activity is important for everyone not only for having good physical health but also for good psychological health which is necessary for a better life and doing better things. Sports provide interaction and communication and develop cooperation between individuals (Zhao \& Chen, 2018).

We can add sports to factors such as family, environment, and education system which affect the psychological wellbeing of adolescents. Exercise contributes both to the reduction of some psychological problems and to increase satisfaction from life. It should not be forgotten that active and healthy individuals will be more determined and active in finding solutions to their problems (Eklund \& Tenenbaum, 2013).

Based on the findings of the current study, the specialists should go beyond pathology or the presence or absence of dysfunction. They should interact well with their patients, fulfill their needs, pay attention to their requests, and help them to feel calm and secure. Given the positive effect of physical activity on psychological health, particularly psychological wellbeing, managers could provide proper structures for encouraging patients to perform physical activities regularly.

Since the present study was conducted in a specific geographical area, a similar study is recommended to conduct throughout the country to generalize the results. One of the most important limitations of the present study is that the sample was limited for participating in the research.

\section{Conclusion}

According to the results of the present study, physical activity improves the social and psychological health of patients. Therefore, the Ministry of Sports and Health authorities and all people who have responsibility for public health, especially about cardiac patients, should be more sensitive to sports and physical activity. The development of short-term and long-term plans for improving wellbeing could be beneficial.

\section{Ethical Considerations}

\section{Compliance with ethical guidelines}

All ethical principles were considered in this article. The participants were informed about the purpose of the research and its implementation; they were also assured about the confidentiality of their information. Moreover, they were allowed to leave the study whenever they wish, and if desired, the results of the research would be available to them. The code of ethics has been issued by the Ethics Committee, Guilan University of Medical Sciences, Rasht, Iran (IR.GUMS.REC.1394.423).

\section{Funding}

This study was financially supported by the research and technology directorate of Guilan University of Medical Sciences, Rasht, Iran.

\section{Authors' contributions}

All authors contributed to designing, conducting, and writing the article.

\section{Conflict of interest}

The authors declared no conflict of interest.

\section{Acknowledgments}

The authors would like to appreciate the vice-chancellor for research and technology of the Guilan university, the head and staff members of Dr. Heshmat hospital and all patients who voluntarily participated in this study.

\section{References}

Bikmoradi, A., Harorani, M., Roshanaei, Gh., Moradkhani, Sh., \& Falahinia, G. H. (2016). The effect of inhalation aromatherapy with damask rose (Rosa damascena) essence on the pain intensity after dressing in patients with burns: A clinical randomized trial. Iranian Journal of Nursing and Midwifery Research, 21(3), 247-54. [DOI:10.4103/1735-9066.180380] [PMID] [PMCID]

Boehm, J. K., Trudel-Fitzgerald, C., Kivimaki, M., \& Kubzansky, L. D. (2015). The prospective association between positive psychological well-being and diabetes. Health Psychology, 34(10), 1013-21. [DOI:10.1037/hea0000200] [PMID] [PMCID]

Borji, M., Bastami, M. R., Bastami, Y., Azami, M., \& Tavan, H. (2015). [Physical activity among elderly people with heart disease (Persian)]. Iranian Journal of Cardiovascular Nursing, 4(2), 54-61. http://journal.icns.org.ir/article-1-339-en.html

Ek, A., Ekblom, Ö., Hambraeus, K., Cider, Å., Kallings, L. V., \& Börjesson, M. (2019). Physical inactivity and smoking after myocardial infarction as predictors for readmission and survival: Results from the SWEDEHEART-registry. Clinical Research in Cardiology, 108(3), 324-32. [DOI:10.1007/s00392018-1360-x] [PMID] [PMCID] 
Eklund, R. C., \& Tenenbaum, G., Eds. (2013). Encyclopedia of sport and exercise psychology. Thousand Oaks, CA: SAGE Publications. https://books.google.com/books?id=z51AwAAQBAJ\&dq

Etemad, Z., \& Esmail Nasab, N. (2012). [The relationship between the level of physical activity and some risk factors of coronary heart disease in the university students (Persian)] Scientific Journal of Kurdistan University of Medical Sciences, 17(1), 25-35. http://sjku.muk.ac.ir/article-1-736-en.html

Fibbins, H., Lederman, O., \& Rosenbaum, S. (2020). Get moving: Physical activity and exercise for mental health. In J. C. Badcock \& G. Paulik (Eds.), A clinical introduction to psychosis: Foundations for clinical psychologists and neuropsychologists (pp 493-510). Cambridge, MA: Academic Press. [DOI:10.1016/ B978-0-12-815012-2.00021-3]

Gül, Ö., Çağlayan, H. S., \& Akandere, M. (2017). The effect of sports on the psychological well-being levels of high school students. Journal of Education and Training Studies, 5(5), 72-80. [DOI:10.11114/jets.v5i5.2270]

Habibi-Vatan, M., Noorbakhsh, M., Nourbakhsh, P., \& Navabinejad, Sh. (2017). [The effect of physical activity on resilience, subjective well-being, and work engagement among female employees (Persian)]. Journal of Research in Behavioural Sciences, 15(2), 205-12. http://rbs.mui.ac.ir/article-1-533-en.html

Hauser, R. M., Springer, K. W., \& Pudrovska, T. (2005). Temporal structures of psychological well-being: Continuity or change? Paper presented at Annual Meetings of the Gerontological Society of America, Orlando, FL, 20 November 2005. https:// www.ssc.wisc.edu/ hauser/HSP_Temporal\% 20Structures\%20of\%20PWB_GSA2005_111405a.pdf

Huffman, J. C., Feig, E. H., Millstein, R. A., Freedman, M., Healy, B. C., \& Chung, W. J., et al. (2019). Usefulness of a positive psychology-motivational interviewing intervention to promote positive affect and physical activity after an acute coronary syndrome. The American Journal of Cardiology, 123(12), 1906-14. [DOI:10.1016/j.amjcard.2019.03.023] [PMID] [PMCID]

Jeong, S. W., Kim, S. H., Kang, S. H., Kim, H. J., Yoon, C. H., \& Youn, T. J, et al. (2019). Mortality reduction with physical activity in patients with and without cardiovascular disease. European Heart Journal, 40(43), 3547-55. [DOI:10.1093/eurheartj/ ehz564] [PMID] [PMCID]

Kashani Movahhed, B., Nikfarjad, H., Shahbazpoor, H. R., Davodzadeh, S. K., Molaei, P., \& Molla Mahmoudi, M. (2018) [The relationship between regular physical activity with spiritual intelligence and psychological well-being among the elderly in Tehran (Persian)]. Journal of Research on Religion $\mathcal{E}$ Health, 4(2), 81-93. http://journals.sbmu.ac.ir/en-jrrh/article/view/20689]

Kim, E. S., Kubzansky, L. D., Soo, J., \& Boehm, J. K. (2017). Maintaining healthy behavior: A prospective study of psychological well-being and physical activity. Annals of Behavioral Medicine, 51(3), 337-47. [DOI:10.1007/s12160-016-9856-y] [PMID] [PMCID]

Kronish, I. M., Diaz, K. M., Goldsmith, J., Moise, N., \& Schwartz, J. E. (2017). Objectively measured adherence to physical activity guidelines after acute coronary syndrome. Journal of the American College of Cardiology, 69(9), 1205-7. [DOI:10.1016/j. jacc.2016.10.087] [PMID] [PMCID]

Krueger, A. B., \& Schkade, D. A. (2008). The reliability of subjective well-being measures. Journal of Public Economics, 92(8-9),
1833-45. [DOI:10.1016/j.jpubeco.2007.12.015] [PMID] [PMCID]

Lavie, C. J., Arena, R., Swift, D. L., Johannsen, N. M., Sui, X., \& Lee, D. C., et al. (2015). Exercise and the cardiovascular system: Clinical science and cardiovascular outcomes. Circulation Research, 117(2), 207-19. [DOI:10.1161/CIRCRESAHA.117.305205] [PMID] [PMCID]

Lee, D. C., Pate, R. R., Lavie, C. J., Sui, X., Church, T. S., \& Blair, S N. (2014). Leisure-time running reduces all-cause and cardiovascular mortality risk. Journal of the American College of Cardiology, 64(5), 472-81. [DOI:10.1016/j.jacc.2014.04.058] [PMID] [PMCID]

Mahmoud Alilou, M., Yarmohammadi Vasel, M., Bayat, A., \& Hosseini, S. E. (2016). [Surveying the psychological well-being components of heart patients referred to Ekbatan Hospital of Hamedan, in association with gender, age and education in 2012 (Persian)]. Razi Journal of Medical Sciences, 22(139), 35-45. http:/ /rjms.iums.ac.ir/article-1-3335-en.html

McMahon, S. R., Ades, P. A., \& Thompson, P. D. (2017). The role of cardiac rehabilitation in patients with heart disease Trends in Cardiovascular Medicine, 27(6), 420-5. [DOI:10.1016/j. tcm.2017.02.005] [PMID] [PMCID]

Mohammadi, N., Aghayousefi, A. R., Alipour, A., Sadeghi, M. Nikrahan, G. R., \& Roohafza, H. R. (2018). [The role of psychological well-being indicators in predicting metabolic risk factors in the patients with chronic coronary heart disease (Persian)]. Positive Psychology, 3(3), 17-32. [DOI:10.22108/ PPLS.2018.106032.1213]

Neyse, F., Daneshmandi, M., Sadeghi Sharme, M., \& Ebadi, A (2011). [The effect of earplugs on sleep quality in patients with acute coronary syndrome (Persian)]. Critical Care Nursing, 4(3), 127-34. http://jccnursing.com/article-1-194-en.html

Ricci, N. A., \& Cunha, A. I. L. (2020). Physical exercise for frailty and cardiovascular diseases. In N. Veronese (Ed.), Frailty and cardiovascular diseases, advances in experimental medicine and biology (pp. 115-129). Vol. 1216. Cham: Springer. [DOI:10.1007/978-3-030-33330-0_12] [PMID]

Ryff, C. D. (2014). Psychological well-being revisited: Advances in the science and practice of eudaimonia. Psychotherapy and Psychosomatics, 83(1), 10-28. [DOI:10.1159/000353263] [PMID] [PMCID]

Sohrabi, M., Abedanzade, R., Shetab Boushehri, N., Parsaei, S., \& Jahanbakhsh, H. (2017). [The relationship between psychological well-being and mental toughness among elders: Mediator role of physical activity (Persian)]. Salmand: Iranian Journal of Ageing, 11(4), 538-49. [DOI:10.21859/sija-1104538]

Steinmayr, R., Heyder, A., Naumburg, C., Michels, J., \& Wirthwein, L. (2018). School-related and individual predictors of subjective well-being and academic achievement. Frontiers in Psychology, 9, 2631. [DOI:10.3389/fpsyg.2018.02631] [PMID] [PMCID]

Vahedi, Sh., \& Ghanizadeh, S. (2009). [Path analysis model between intrinsic religious motivation, praying, spiritual wellbeing and quality of life with psychological well-being of college students (Persian)]. Journal of Research in Psychological Health, 3(2), 27-42. http://ensani.ir/fa/article/219115/

van Dierendonck, D. (2004). The construct validity of Ryff's Scales of psychological well-being and its extension with spir- 
itual well-being. Personality and Individual Differences, 36(3), 629-43. [DOI:10.1016/S0191-8869(03)00122-3]

Zhao, M., \& Chen, Sh. (2018). The effects of structured physical activity program on social interaction and communication for children with autism. BioMed Research International, 2018, 1825046. [DOI:10.1155/2018/1825046] [PMID] [PMCID] 
This Page Intentionally Left Blank 